Цитирование: Сытов А.В., Зузов С.А., Кукош М.Ю., Лейдерман И.Н., Потапов А.Л., Хотеев А.Ж. Практические рекомендации по заместительной ферментной терапии при раке поджелудочной железы. Злокачественные опухоли : Практические рекомендации RUSSCO \#3s2, 2021 (том 11). 45

\title{
ПРАКТИЧЕСКИЕ РЕКОМЕНДАЦИИ ПО ЗАМЕСТИТЕЛЬНОЙ ФЕРМЕНТНОЙ ТЕРАПИИ ПРИ РАКЕ ПОДЖЕЛУДОЧНОЙ ЖЕЛЕЗЫ
}

Коллектив авторов: Сытов А.В., Зузов С.А., Кукош М.Ю., Лейдерман И.Н., Потапов А.Л., Хотеев А.Ж.

Ключевые слова: поджелудочная железа, панкреатит, панкреатин

Синдром внешнесекреторной недостаточности при раке поджелудочной железы (ПЖ) обусловлен уменьшением массы ее функционирующей экзокринной паренхимы после операций на Пж (дистальная резекция, панкреато-дуоденальная резекции) при злокачественныхи доброкачественных опухолях, а также при операциях на желудке, осложнённых послеоперационным панкреатитом.

Дефицит эндогенного секретина вызывает нарушения целого ряда функций органов пищеварения: повышается давление в 12-перстной кишке и в панкреатических протоках, отмечается спазм сфинктера Одди, снижается объем панкреатического сока и бикарбонатов. В результате уменьшается секреция жидкой части панкреатического сока, что приводит к его сгущению и повышению в нем концентрации белка, а следовательно, к увеличению вязкости и снижению скорости оттока секрета.

ПЖ обладает огромной резервной возможностью секреции ферментов, поскольку в физиологических условиях она продуцирует около двух литров панкреатического сока в сутки, содержащего в 10 раз больше ферментов и зимогенов, чем требуется для нормального переваривания пищи (физиологическая гиперсекреция).

Здоровая ПЖ при стимулированной секреции вырабатывает не менее 1 млн ЕД липазы в сутки, а развитие симптомов мальабсорбции проявляется лишь при утере функциональности $90 \%$ и более ткани железы.

Клинические проявления экзокринной недостаточности ПЖ зависит от ряда вторичных факторов, включающих особенности гастринтестинальной моторики, желудочной, билиарной и тонкокишечной секреции, абсорбции, секреции гормонов и последствий абдоминальной хирургии. Коррекция вышеуказанных нарушений может не только способствовать уменьшению проявлений внешнесекреторной панкреатической недостаточности, но и полному ее купированию.

Синдром мальабсорбции при раке ПЖ имеет вторичный характер. В зависимости от тяжести проявлений выделяют: легкую (І степени), среднетяжелую (ІІ степени) и тяжелую (III степени). 
Различают местные и общие проявления синдрома мальабсорбции.

Местные нарушения:

- морфологические изменения слизистой оболочки (дистрофическо-атрофические изменения слизистой оболочки, укорочение и уплощение ворсин),

- нарушение работы ферментныхи транспортных систем тонкой кишки,

- расстройства моторики,

- развитие синдрома избыточного бактериального роста в тонкой кишке,

- развитие диареи (осмотического типа).

Общие нарушения включают нарушение всасывания белков, жиров, углеводов, витаминов, микроэлементов, желчных кислот и нарушения всех видов обмена: белкового, жирового, углеводного, водно-электролитного, минерального, витаминного, гормонального.

\section{1. КЛИНИЧЕСКИЕ ПРОЯВЛЕНИЯ}

- Диарея с полифекалией (масса кала более 300 г/сут)

- Болевой абдоминальный синдром

- Кишечный дискомфорт (метеоризм, урчание, флатуленция)

- Похудание

- Геморрагический синдром

- Общий анемический синдром

- Сидеропенический синдром

- Дисэлектролитный (гипокальциемический, гипокалиемический, гипонатриемический, гипомагниемический) синдром

- Гиповитаминоз

- Синдром белково-энергетической недостаточности.

\section{2. ДИАГНОСТИКА}

1. Клинический анализ крови: макромикроцитарная анемия;

2. Биохимический анализ крови: нарушения белкового, жирового, углеводного, электролитного обмена;

3. Коагулограмма: гипопротромбинемия, гипофибриногенемия;

3. Определение в крови уровня витамина В12, фолиевой кислоты, железа, ферритина;

4. Тест на толерантность к глюкозе: плоская гликемическая кривая;

5. Исследования кала: масса суточного кала более 300 г/сут, цвет (желтый, зеленый), $\mathrm{pH}$, вид (пенистый, блестящий), запах (кислый, гнилостный), примеси; анализ на эластазу 1, химотрипсин;

6. Гормональные исследования: повышение серотонина, гистамина. 


\section{3. ЛЕЧЕНИЕ}

Ферментные препараты, используемые для заместительной терапии, делятся на шесть групп:

- Экстракты слизистой оболочки желудка, основным действующим веществом которых является пепсин;

- Панкреатические энзимы: амилаза, липаза и трипсин;

- Комбинированные препараты, содержащие панкреатин в сочетании с компонентами желчи, гемицеллюлозой и прочими дополнениями;

- Растительные энзимы: папаин, грибковая амилаза, липаза и другие ферменты;

- Комбинированные ферментные препараты, содержащие панкреатин в сочетании с растительными энзимами, витаминами;

- Дисахаридазы.

Наиболее универсальными средствами, нормализующими пищеварение при синдромах мальдигестии и мальабсорбции, являются препараты панкреатина, не оказывающие влияния на функцию желудка, печени, моторику билиарной системы и кишечника. Входящая в полиферментный комплекс амилаза расщепляет преимущественно внеклеточные полисахариды до простых сахаров - сахарозы и мальтозы, практически не участвуя в гидролизе растительной клетчатки. Протеазы в препаратах панкреатина преимущественно представлены химотрипсином и трипсином. Липаза участвует в гидролизе нейтрального жира. Минимальная доза липазы, необходимая для адекватной ферментной заместительной терапии, составляет около 100 тыс. Ед/сут. Традиционно рекомендуется назначать 40 тыс Ед липазы на основной приём пищи, от 10 до 25 тыс Ед в зависимости от калорийности принимаемых продуктов - на промежуточный. Предпочтение отдаётся микрогранулированным препаратам, которые можно отнести к самым современным полиферментным препаратам заместительной ферментной терапии. Лекарственными средствами, полностью удовлетворяющими вышеуказанным требованиям и используемыми в последнее время, являются высокоактивные полиферментные препараты панкреатина в виде минимикросфер, покрытых энтеросолюбильной оболочкой, размер которых уменьшен до 1 мм. Это обеспечивает иную, чем при применении микросфер и микротаблеток фармакокинетику, способствует оптимальному перемешиванию с пищей и повышает эффективность препарата в среднем на $25 \%$. Решение о выборе дозы ферментного препарата должно приниматься индивидуально для каждого больного. При выборе активности ферментов, входящих в состав препарата, можно руководствоваться данными активности фекальной эластазы, снижение содержания которой свидетельствует о выраженности экзокринной недостаточности поджелудочной железы. Эластазный тест является в настоящее время самым информативным и доступным из неинвазивных методов оценки состояния внешнесекреторной функции поджелудочной железы. Ряд исследований показал клиническую целесообразность ориентации на уровень фекальной эластазы при первичном выборе дозы. В зависимости от степени внешнесекреторной недостаточности назначается дифференцированная полиферментная терапия. 
Ферментные препараты с внешнесекреторной недостаточностью назначают пожизненно, однако доза может варьировать в зависимости от многих факторов, в том числе и от соблюдения больным диеты. Таким образом, решение о выборе дозы ферментного препарата должно приниматься индивидуально для каждого больного.

Рекомендации по подборудозы полиферментного препарата ${ }^{1}$ в соответствии с данными фекальной эластазы представлены в табл. 1.

Таблица 1. Принципы подбора доз полиферментного препарата

\begin{tabular}{|l|l|l|}
\hline $\begin{array}{l}\text { Состояние экзокринной функции } \\
\text { поджелудочной железы }\end{array}$ & $\begin{array}{l}\text { Данные эластазы } \\
\text { кала (мкг/г) }\end{array}$ & $\begin{array}{l}\text { Рекомендуемая доза } \\
\text { препарата Ед FIP липазы/сут. }\end{array}$ \\
\hline Нормальная экзокринная функция & $>200$ & 50000 \\
\hline Умеренно выраженная экзокринная недостаточность & $100-199$ & 100000 \\
\hline Выраженная экзокринная недостаточность & $<100$ & 150000 \\
\hline
\end{tabular}

Комплексная диагностика и адекватный подбор дозы ферментных препаратов не гарантирует абсолютную эффективность ферментной терапии.

Причинами неэффективности терапии являются:

- Кислотная агрессия при прохождении через желудок. Такая ситуация может возникнуть у пациентов после панкреатодуоденальной резекции в связи с замедленной эвакуацией из желудка, которая ведёт к закономерному увеличению экспозиции кислоты. Необходимо назначение антисекреторной терапии (ингибиторы протонной помпы);

- Некорректная фармакокинетика ферментныхпрепаратов. Чем лучше перемешивание с химусом, тем больше контакт фермента со своим субстратом, а чем меньше размер частиц препарата, тем легче ферментный препарат подвергнется эвакуации по этапам пищеварения. Существенное значение имеет рекомендация принимать ферментный препарат непосредственно в начале приёма пищи, т. к. в таких условиях обеспечивается лучшее смешивание с химусом;

- Назначение неадекватно низких доз ферментов (в том числе микрокапсулированных) для снижения общей стоимости лечения.

1 Только для микрокапсулированных препаратов панкреатина в энтеросолюбильной оболочке. 